\title{
Spontaneous pneumothorax: comparison of simple drainage, talc pleurodesis, and tetracycline pleurodesis
}

\author{
MERETE ALMIND, PETER LANGE, KAJ VISKUM \\ From Medical Department P, Chest Clinic, Bispebjerg Hospital, Copenhagen, Denmark
}

\begin{abstract}
From 1978 to 198596 patients with their first spontaneous pneumothorax were randomised into three groups, receiving either treatment with simple drainage (34 patients), drainage with tetracycline pleurodesis (33 patients), or drainage with talc pleurodesis ( 29 patients). There were 58 men and 38 women, aged $18-88$ years. There was no significant difference between the three groups in the mean time in hospital or the period for which the drains were retained. The incidence of infection, persistent pneumothorax, and relapse while in hospital was also similar for the three groups. At follow up in 198789 patients could be accounted for, with an average follow up period of 4.6 years. The incidence of recurrence was $36 \%$ in the simple drainage group, $13 \%$ in the tetracycline pleurodesis group, and $8 \%$ in the talc pleurodesis group. The difference between the talc and simple drainage groups was significant. None of the methods caused severe short or long term side effects or changes in the follow up chest radiograph. Thoracoscopy, performed on admission in 85 patients, showed normal appearances in 73 patients and small cysts in 12. The thoracoscopic findings were of no value in predicting recurrence. Talc pleurodesis resulted in a significantly lower recurrence rate than simple drainage, tetracycline pleurodesis having intermediate efficacy.
\end{abstract}

\section{Introduction}

Spontaneous pneumothorax may occur in subjects with no history of lung disease (idiopathic) or in those with pre-existing lung disease (secondary), and it often recurs. The recurrence rate is lower in idiopathic than in secondary spontaneous pneumothorax, but the figures vary (from $20 \%$ to $50 \%$ ) in published reports, depending on the selection of patients. ${ }^{1-4}$ Not surprisingly therefore, approaches to treatment have varied considerably, and have included observation ${ }^{5}$; aspiration ${ }^{6}$; pleural drainage with or without suction $^{278-12}$; pleurodesis with silver nitrate, ${ }^{213}$ tetracycline, ${ }^{1114}$ talc, ${ }^{31516}$ quinacrine,${ }^{18}$ and fibrin glue ${ }^{19}$; and thoracotomy with resection of cysts or with pleurodesis induced by brushing the pleural surface ${ }^{82021}$ or both. The choice of treatment is influenced by the size of the pneumothorax, clinical symptoms, local practices, technical possibilities, and the presumed recurrence rate. The finding of cysts on the chest radiograph or at thoracoscopy has favoured a

Address for correspondence: Dr Kaj Viskum, Medical Department P, Bispebjerg Hospital, Bispebierg Bakke 23, DK-2400 Copenhagen NV, Denmark. (Reprints will be available)

Accepted 20 April 1989 more invasive approach. ${ }^{313162021}$ Previous workers have argued in favour of a specific treatment, but only a few ${ }^{211}$ have performed controlled studies. Wied and coworkers compared drainage alone with drainage plus silver nitrate pleurodesis in a randomised study, ${ }^{2}$ finding a recurrence rate of $45 \%$ in the group having drainage compared with no recurrence in the group having pleurodesis. In a further study by the same group patients with a first episode of idiopathic spontaneous pneumothorax were randomised to receive either silver nitrate pleurodesis or tetracycline pleurodesis." There were no recurrences in either group, but those having tetracycline pleurodesis had less pleural exudate and required less analgesia.

The aim of our randomised, prospective study was to compare the efficacy of three widely used methods in the treatment of a first episode of spontaneous pneumothorax, whether idiopathic or secondary. Patients were followed up to determine recurrence rates, mean time in hospital, and serious side effects with the three forms of treatment.

\section{Methods}

PATIENTS

All patients presenting during $1978-85$ with a first 
episode of spontaneous pneumothorax were included in the study. The 96 patients were stratified according to sex and age before being randomised into three groups, receiving treatment with simple drainage, drainage with tetracycline pleurodesis, or drainage with talc pleurodesis. The distribution according to sex, age (range 18-88 years), and treatment is shown in table 1. Patients were not stratified according to the cause of pneumothorax; of the 25 patients with secondary spontaneous pneumothorax, six received simple drainage, nine tetracycline pleurodesis, and 10 talc pleurodesis.

\section{TREATMENT}

For drainage a 22 Nelaton catheter was inserted in all patients, usually through the 6th intercostal space in the mid axillary line. Pleurodesis was induced with either tetracycline (Reverine), $550 \mathrm{mg}$ in $20 \mathrm{ml}$ sterile water, or talc (Pharmacopea Danica), 5 g suspended in $250 \mathrm{ml}$ isotonic saline. The solutions were instilled through the drain before the lung was expanded to distribute the pleural irritants over the pleural surface. This was facilitated by placing the patient in different positions briefly and then on the contralateral side for two hours. After instillation of tetracycline or talc the drain was clamped for two hours, after which suction of $20-30 \mathrm{~cm} \mathrm{H}_{2} \mathrm{O}$ was applied. Pleural drainage was continued until the lung was totally expanded, no air had escaped for 24 hours, and the volume of fluid drained was less than $50-100 \mathrm{ml}$ in 24 hours. Drains were examined for bacterial growth after removal.

\section{FOLLOW UP}

In autumn 1987 the 96 subjects were traced through the population register. Death certificates were obtained for the 16 patients who had died. Two had emigrated and their fate is unknown. Seventy eight were therefore invited to have a chest radiograph and to fill in a questionnaire. Of these, 51 had a chest radiograph and completed the questionnaire, and 22 filled in the questionnaire only. The mean follow up period for these patients was 4.6 years and did not differ in the three groups. Five subjects failed to respond. It was possible to ascertain whether the nonresponders had been in contact with the local chest clinic recently.

Table 1 Distribution of 96 patients according to age, sex, and treatment

\begin{tabular}{|c|c|c|c|c|c|c|}
\hline \multirow[b]{2}{*}{ Age (y) } & \multicolumn{2}{|c|}{ Simple drainage } & \multicolumn{2}{|c|}{ Tetracycline } & \multicolumn{2}{|c|}{ Talc } \\
\hline & $M$ & $F$ & $M$ & $F$ & $M$ & $F$ \\
\hline $\begin{array}{l}18-40 \\
41-70 \\
>\quad 70 \\
\text { Total }\end{array}$ & $\begin{array}{r}10 \\
9 \\
4 \\
23\end{array}$ & $\begin{array}{r}8 \\
2 \\
1 \\
11\end{array}$ & $\begin{array}{r}11 \\
4 \\
5 \\
20\end{array}$ & $\begin{array}{r}10 \\
3 \\
0 \\
13\end{array}$ & $\begin{array}{r}9 \\
3 \\
3 \\
15\end{array}$ & $\begin{array}{r}9 \\
4 \\
1 \\
14\end{array}$ \\
\hline
\end{tabular}

\section{ANALYSIS OF RESULTS}

Almind, Lange, Viskun 그ำ

Results were analysed by the $\chi^{2}$ test for unpaired data or by Student's $t$ test; $p$ values of $\leqslant 0.05$ were considered significant.

\section{Results}

Of the 16 patients who had died, two, aged 85 and 81 years, had died in hospital 20 and 12 days after simple drainage and after tetracycline pleurodesis respect tively. Both had chronic obstructive pulmonary dise ease. Necropsy showed that there was atelectasis in the lung on the side of the pneumothorax in both patients but that the cause of death was pulmonary embolisn in the first case and bilateral pneumonia in the seconds Death in the other 14 patients was not related tQ treatment, though in 10 it was due to pulmonares causes (all had chronic obstructive lung disease). The. period between treatment and death ranged from fou months to eight years. Four patients died from nore pulmonary causes seven months to six years afte? treatment.

Neither the period in hospital (table 2) nor th\& duration of pleural drainage (table 3 ) differed significantly between the three groups. All patients had $\mathbb{D}$ temperature of $37.5^{\circ} \mathrm{C}$ or more after treatment. The pyrexia lasted for a mean of 2.4 days in the grou having drainage only, 1.9 days in the tetracycline pleurodesis group, and 2.9 days in the talc pleurodesis group. The difference in time between the talc and the tetracycline group was significant.

No empyema occurred. Nine patients had pneumonia during their hospital stay, three in each. group. Twenty three patients had persisten pneumothorax (defined as pneumothorax on the side receiving treatment after three days), 10 patients in the drainage group, four in the tetracycline pleurodesis group, and nine in the talc pleurodesis group (differen ces not significant). In 13 of the 23 patients increased

Table 2 Length of hospital stay for the three treatment groups

\begin{tabular}{lllll}
\hline $\begin{array}{l}\text { No of } \\
\text { days }\end{array}$ & $\begin{array}{l}\text { Simple drainage } \\
(n=34)\end{array}$ & $\begin{array}{l}\text { Tetracycline } \\
(n=33)\end{array}$ & $\begin{array}{l}\text { Talc } \\
(n=29 \rho\end{array}$ \\
\hline Mean & 6.80 & 6.00 & 6.60 & O \\
Range & $2-24$ & $3-23$ & $3-18$ & $\omega$ \\
SD & 5.56 & 4.64 & 4.22 & $\sigma$ \\
\hline
\end{tabular}

Table 3 Duration of drainage for the three treatment group

\begin{tabular}{|c|c|c|c|}
\hline $\begin{array}{l}\text { No of } \\
\text { days }\end{array}$ & $\begin{array}{l}\text { Simple drainage } \\
(n=34)\end{array}$ & $\begin{array}{l}\text { Tetracycline } \\
(n=33)\end{array}$ & 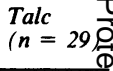 \\
\hline $\begin{array}{l}\text { Mean } \\
\text { Range } \\
\text { SD }\end{array}$ & $\begin{array}{l}4 \cdot 35 \\
1-18 \\
3 \cdot 42\end{array}$ & $\begin{array}{l}3 \cdot 10 \\
2-7 \\
0 \cdot 95\end{array}$ & $\begin{array}{l}4 \cdot 21 \\
2-14 \\
2 \cdot 67\end{array}$ \\
\hline
\end{tabular}


suction via the initial drain was followed by re-expansion of the lung. In seven patients either one or two additional drains had to be inserted. Three patients have been excluded from follow up: two patients in the drainage only group had to have the initial treatment supplemented by pleurodesis and one needed a thoracotomy to expand the lung. The number of relapses during the period in hospital after removal of the drain did not differ significantly between the three groups (four subjects in the drainage group, three in the tetracycline group, and one in the talc group).

During the total follow up period ipsilateral recurrence was significantly more common in patients receiving simple drainage (nine out of 25) than in those receiving talc pleurodesis (two out of 24). Recurrences in those receiving tetracycline (three out of 23) did not differ significantly from either of the other two groups. Contralateral pneumothorax occurred in five of the 73 patients followed up.

\section{THORACOSCOPY}

Thoracoscopy was performed in 85 patients, of whom 73 had normal pleural surfaces or a few traces of fibrin only. Twelve patients had bullae or cysts or both and these patients were equally distributed between the three groups. Eleven of the patients with cysts and 54 with normal appearances at thoracoscopy were available for evaluation. One patient with a cyst $(9 \%)$ and 12 with normal appearances $(22 \%)$ had had a recurrence (difference not significant).

\section{PAIN DURING THE PROCEDURE AND AT FOLLOW UP}

Pain during the intervention was reported by $18(69 \%)$ of those having drainage only, $17(74 \%)$ in the tetracycline group, and $14(58 \%)$ in the talc group (differences not significant). At follow up occasional lancinating pleural pain on deep inspiration was reported by significantly more of the talc group (9) than of the tetracycline (3) or the simple drainage groups (3). The pain was mild, had not made the patients visit their doctor, and was unveiled only when a specific question was asked. The number of patients reporting stiffness of the chest on deep inspiration at follow up did not differ significantly between those having drainage only (5), tetracycline (2), and talc (4).

\section{CHEST RADIOGRAPH AT FOLLOW UP}

At follow up 10 of those who had had talc pleurodesis had obliteration of the lateral costophrenic angle on the chest radiograph, significantly more than in the drainage only (4) and the tetracycline groups (1). No case of severe pleural thickening was observed.

\section{Discussion}

In studies of patients with both idiopathic and secondary spontaneous pneumothorax the rates of recurrence have varied, presumably depending on selection of patients. ${ }^{1-5101322}$ No study can claim to be truly cross sectional. Some authors suggest that simple drainage does not lower the recurrence rate. ${ }^{34} \mathrm{~A}$ policy of no interference or simple needle aspiration is unlikely to influence the recurrence rate. Information on this is, however, available only from uncontrolled studies of a few patients. ${ }^{56}$ The recurrence rate after pleurodesis has varied considerably (4-28\%), depending on the selection of patients and also on the material used for the pleurodesis. ${ }^{313-19}$ Surgical procedures such as thoracotomy with scrubbing of the pleural surface or parietal pleurectomy have been shown to result in very low recurrence rates $(0 \cdot 4-2 \cdot 3 \%){ }^{20}$

The choice of treatment is difficult when the physician is confronted with an individual patient. ${ }^{21}$ Even if it were certain that $40 \%$ would have a recurrence and $60 \%$ would not if treated with simple drainage, the approach would still depend on the physician's attitude to this information. Some would say that there should be the minimum interference necessary to relieve symptoms as $60 \%$ of the patients would have no recurrence; others would institute more aggressive treatment to prevent recurrence in the other $40 \%$, and would thereby treat $60 \%$ unnecessarily intensively by performing a pleurodesis. Our study was not intended to provide an answer to this problem but to elucidate which of three widely used treatments is best. We found that time in hospital, duration of drainage, and discomfort to the patient were about equal in the three groups. The cost of the three treatments varies little as talc and tetracycline are cheap. In our study thoracoscopy was performed in 85 patients in the hope that this investigation, as in other studies, ${ }^{314}$ could help to predict the patients who were likely to have a recurrence. This unfortunately it did not do in our study. The discrepancy between the results of our study and previous studies is difficult to explain. Thoracoscopy was performed by several doctors as an acute service and this may reduce the value of the investigation. Small collapsed cysts may have been overlooked.

Talc pleurodesis in our study was associated with the smallest number of recurrences. The only side effects, apart from more prolonged fever, were the more frequent episodes of lancing chest pain and the higher frequency of obliteration of the lateral costophrenic angle.

Infection of the pleural cavity was not observed in our study. The rise in temperature, which was greatest in the group treated with talc, could be interpreted as a sign of a more pronounced sterile pleurisy in these 
patients-which again could explain why this treatment resulted in the lowest recurrence rate.

The more extensive pleural changes on the chest radiographs of the patients in the group treated with talc might suggest that pulmonary function had been reduced. We did not measure pulmonary function at follow up, but in a previous study of similar patients we found an insignificant restrictive impairment of pulmonary function after talc poudrage. ${ }^{23}$ It has been suggested that possible pollution of talc with asbestos could constitute a risk factor for development of mesothelioma. No cases of mesothelioma, however, have been reported in studies from the United Kingdom $^{24}$ or Denmark ${ }^{23}$ despite fairly long observation periods. These findings support the use of talc pleurodesis in the treatment of spontaneous pneumothorax when avoidance of recurrence is considered to be important.

This study was supported by a grant from the National Union for the Fight Against Pulmonary Diseases.

\section{References}

1 Kjaergaard H. Spontaneous pneumothorax in the apparently healthy. Acta Med Scand 1932;43(suppl): 1-159.

2 Wied U, Andersen K, Schultz A, Rasmussen E, WattBoolsen S. Silver nitrate pleurodesis in spontaneous pneumothorax. Scand J Thorac Cardiovasc Surg 1981; 15:305-7.

3 Verschoof AC, Ten Velde GPM, Greve LH, Wouters EFM. Thoracoscopic pleurodesis in the Management of Spontaneous Pneumothorax. Respiration 1988;53: 197-200.

4 Andersen B, Brøndum Nielsen J. Recurrence Risk in Spontaneous Pneumothorax. A follow up of 178 initial occurrences in a Danish county in a ten-year period. Acta Chir Scand 1965;356(suppl):160-6.

5 Stradling P, Poole G. Conservative Management of Spontaneous Pneumothorax. Thorax 1966;21:145-9.

6 Hamilton AAD, Archer GJ. Treatment of pneumothorax by simple aspiration. Thorax 1983;38:934-6.

7 Videm V, Pillgram-Larsen J, Ellingsen $\emptyset$, Andersen G, Øvrum E. Spontaneous pneumothorax in chronic obstructive pulmonary disease: complications, treatment and recurrences. Eur $J$ Respir Dis 1987;71: 365-71.
8 Granke K, Fischer CR, Gago O, Morris JD, Prager RL The Efficacy and Timing of Operative Intervention for $\overrightarrow{\bar{?}}$ Spontaneous Pneumothorax. Ann Thorac Surg 1986;0 42:540-2.

9 So S, Yu D. Catheter drainage of spontaneous pneumo thorax: suction or no suction, early or late removal? Thorax 1982;37:46-8.

10 Mattila S, Kostiainen S. Spontaneous pneumothorax Scand J Cardiovasc Surg 1977;11:259-63.

11 Wied U, Halkier E, Hoeier-Madsen K, Plucnar B; Rasmussen E, Sparup J. Tetracycline versus silver $\vec{\omega}$ nitrate pleurodesis in spontaneous pneumothorax? $J$ Thorac Cardiovasc Surg 1983;86:591-3.

12 Conces DJ. Treatment of pneumothorax utilizing smaller caliber chest tubes. Chest 1988;94/1:55-7.

13 Nissen H. Pneumothorax spontaneus [thesis]. København Munksgaard, 1969.

14 Krasnik M, Christensen B, Halkier E, Høier-Madsen $\mathrm{K}_{0}$ Jelnes R, Wied U. Pleurodesis in spontaneous pneumothorax by means of tetracycline. Follow-up evaluation of a method. Scand $J$ Cardiovasc Surg 1987;21:181-2.

15 Guerin JC, Champel F, Biron E, Kalb JC. Pleural talc a thoracoscopy in the treatment of a pneumothorax. RevMal Respir 1985;2:25-9.

16 Smith WG, Rothwell PBG. Treatment of spontaneous pneumothorax. Thorax 1962;17:342-9.

17 Vanderschueren RG. Le talcage pleural dans les pneumothorax spontané. Poumon-Coeur 1981;37 273-6.

18 Larrieu AJ, Tyers FO, Williams EH, O’Neill MJ, Derrick مึ JR. Intrapleural instillation of quinacrine for treatmen? of recurrent spontaneous pneumothorax. Ann Thora $\overrightarrow{\widehat{\sigma}}$ Surg 1979;28:146-50.

19 Heindl W, Pridun N. The endoscopic fibrin pleurodesis in the complicated pneumothorax. (in press).

20 Weeden D, Smith GH. Surgical experience in the management of spontaneous pneumothorax, 1972-82 Thorax 1983;38:737-43.

21 Harvey JE, Jeyasingham K. The difficult pneumothorax $\underset{\bar{\sigma}}{\times}$ Br J Dis Chest 1987;81:209-16.

22 Wilson KS. Spontaneous pneumothorax: a ten-yea study. Military Med 1970;Feb:95-9.

23 Lange P, Mortensen J, Groth S. Lung function 22-3로 years after treatment of idiopathic spontaneous pneumothorax with talc poudrage or simple drainage. Thorax 1988;43:559-61.

24 Research Committee of the British Thoracic Association and the Medical Research Council Pneumoconiosis Unit. The survey of long-term effects of talc and kaolin pleurodesis. Br J Dis Chest 1979;73:285-8. 